\section{An interactive computer program to optimize data categorization}

\author{
GIDEON VIGDERHOUS and PAUL OELTJEN \\ Survey Research Group, Bell Canada, Montreal, P. Q., Canada
}

Description. This program was written in order to enable the researcher to categorize univariate distribution by minimizing the amount of information lost resulting from such a procedure. This program will indicate which categories should be collapsed by minimizing the information lost, given that the number of categories for collapsing the data are supplied by the researcher.

The mathematical discussion and procedure for data categorization is discussed (Bryson \& Phillips, 1975) and is achieved by dividing a frequency distribution $f(x)$ into $L$ homogenous groups where boundaries $b_{1}, b_{2} \cdots b_{1-1}$ are placed in such a way that:

$$
\sum_{A}^{b_{1}} \sqrt{f(x)}=\sum_{x=b_{1}+1}^{b_{2}} \sqrt{f(x)}=\cdots=\sum_{x=b_{L}-1+1}^{B} \sqrt{f(x)}
$$

where A and B denote the lowest and highest values of $x$.

Program Language. Fortran IV.

Computer. The program was originally written and tested for Honeywell 6000.

Restrictions. Since the initial input data is categorized, no problems are anticipated in information input. This program is written in an interactive mode; however, with few modifications, the program could be adjusted to other computer systems.

Program Input. (1) Number of categories of the original data set. (2) The observed frequency for each category. (3) The desired number of categories for reclassifying the data.

Program Output. (1) The observed frequency for each category $x$. $[f(x)]$. (2) The square root of the frequency for each category $\sqrt{\mathrm{f}(\mathrm{x})}$. (3) The cumulative distribution of $\sqrt{\mathrm{f}(\mathrm{x})}$. (4) The optimal division of categories (old categories should be
*RIIN INTERVAI

\section{PROGRAM TO OPTIMIZE DATA CATEGORIZATION}

TO START A NEW RUN WITH NEW DATA

TELL THE PROGRAM TO COLLAPSE YOUR DATA INTO O CATEGORIES

TO TERMI NATE THE RIIN

IELL. THE PROGRAM TO COLLAPSE YOUR DATA INTO - 1 CATEGORIES

NUMBER OF CATEGORIES OF ORIGINAL DATA?
$=10$

ENTER THE OBSERVED FREOUENCY FOR EACH CATEGORY

$=12,23,34,5,56,12,3,14,10,23$

\begin{tabular}{|c|c|c|c|}
\hline $\begin{array}{l}\text { OLD } \\
\text { CATE- } \\
\text { GORY }\end{array}$ & F & SORT(F) & ClM (SORT (F)) \\
\hline 1 & 12. & 3.45410 & 3.46410 \\
\hline 2 & 23. & 4.79583 & 0.25993 \\
\hline 3 & 34. & 5.83095 & 14.09080 \\
\hline 4 & $5:$ & 2.23607 & 16.32695 \\
\hline 5 & 56. & $7.4833 i$ & 23.81027 \\
\hline 6 & 12. & 3.46410 & 27.27437 \\
\hline$?$ & 3 & 1.73205 & 29.00642 \\
\hline 8 & 14 & 3.74166 & 32.74898 \\
\hline 9 & 10. & 3.15228 & 35.91036 \\
\hline 10 & 23 & 4.79583 & 40.70510 \\
\hline
\end{tabular}

INTO HOW MANY CATEGORIFS DO YOU WISH TO COLLAPSE YOIR DAIA?

$\begin{array}{ccc}\begin{array}{c}\text { NEW } \\ \text { CATEGORY }\end{array} & \begin{array}{c}\text { OLD } \\ \text { CATEGORY }\end{array} & \text { FREOUFNCY } \\ 1 & 1-1 & 12 . \\ 2 & 2=3 & 57 . \\ 3 & 4=4 & 5 . \\ 4 & 5=5 & 56 . \\ 5 & 6=7 & 15 . \\ 6 & 8-9 & 24 . \\ 7 & 10-10 & 23 .\end{array}$

INTO HOW MANY CATEGORIES DO YOU WISH TO COLLAPSE YOUR DATA? $=4$

$\begin{array}{ccc}\text { NEW } & \text { OL.D } \\ \text { CATEGORY } & \text { CATERORY } & \text { FREOLENCY } \\ 1 & 1-2 & 35 \\ 2 & 3=5 & 95 \\ 3 & 5=7 & 15 . \\ 4 & 8=10 & 47 .\end{array}$

INTO HOW MANY CATEGORIFS DO YOU WISH TO COLLAPSE YOUR DATA? READY
*LjST interval

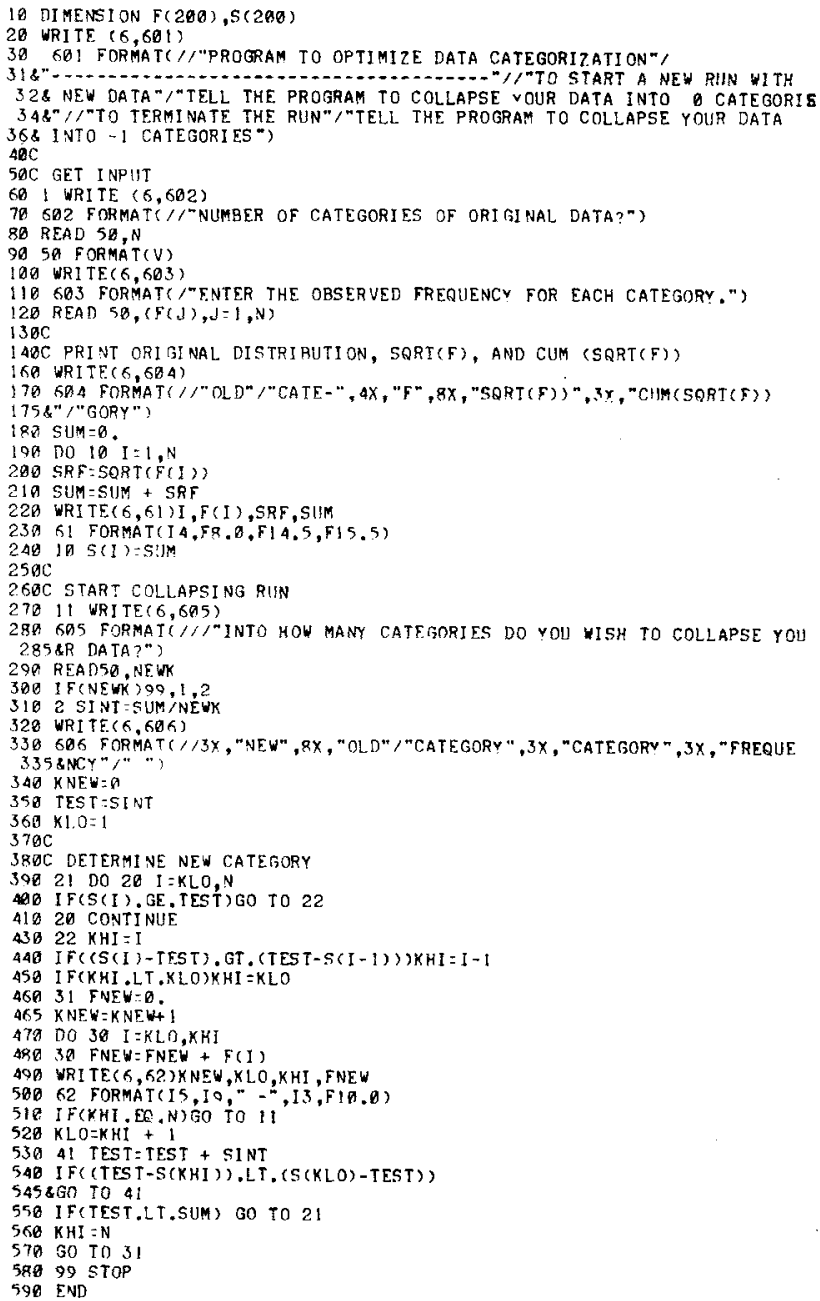


collapsed into new categories). (5) The frequency observed for each new category after recollapsing the data.

Availability. The program printout and user instruction may be obtained without cost from:

\section{G. Vigderhous \\ Bell Canada}

620 Belmont, Room 1120

Montreal, P. Q., Canada.

\section{REFERENCE}

BRYson, K. R., \& Phillips, D. P. Method for classifying interval-scale and ordinal-scale data. Sociological Methodology, 1975. Pp. 171-190. San Francisco: The Jossey Bass Series, 1974.

\section{Behavior Research Methods \& Instrumentation 1975, Vol. 7(5), 476 \\ CMTG: A Fortran IV Program for studying individual behavior in the common target game}

\section{FRANK A. MORISANO and VICTOR REZMOVIC Syracuse University, Syracuse, New York 13210}

The common target game was devised as a method for studying group problem solving (Leavitt, 1960). The game requires the members of a group to work together to solve problems under conditions of limited information. Each of three group members must contribute a number from 0 to 10 toward a target number between 3 and 30 , previously specified by the experimenter. Most recently, Joyner (Joyner, 1970; Joyner \& Green, 1970; Joyner, Note 1) has used computer techniques in developing and testing an information processing model of concept formation by individuals playing the common target game. Computerized procedures would appear to offer an effective way for studying the behavior of individuals interacting under highly controlled conditions. CMTG was written as a medium for conditioning subjects to solve problems presented according to specified solution strategies under either a cooperative or a competitive set (Morisano, Note 2).

Description. CMTG is an interactive computer version of the three-person common target game. The subject, working at a remote terminal, is presented with a description of the task and instructions for playing the game. He is informed that the responses of the other two members of his group will be determined by the program and that the goal of the group will be to develop a system for solving any target number on the first attempt. A series of randomly ordered target numbers is presented. The subject enters his contribution and then receives feedback concerning the responses of the two simulated members of his group, whether the group was successful in hitting the target on that trial, and the number of points earned. The responses of the simulated subjects are selected from among three general solution strategies referred to as TWOs, THREEs, and TENs (Joyner, 1970). Each of these strategies involves three different roles for partitioning target numbers. Each group

The authors would like to express their appreciation to Sidney J. Arenson and Edward J. O'Connell for their assistance in the development of CMTG. member must adopt one of the roles if the group is to succeed. Points can be earned on either an individual or a group contingency basis. It is thus possible to require the subject to learn to respond according to up to nine different strategy-role combinations to be successful. The criterion for learning of a strategy-role combination is seven consecutive correct target number solutions. A new combination is automatically introduced when the subject reaches criterion for the previous one. In the present version, the game terminates following exposure to nine combinations.

Input. Before the subject is seated at the terminal, the experimenter must initialize a set of parameters that determine the strategy-role combinations the subject will receive, the order in which these will be presented, and the type of feedback provided (individual or group contingency).

Language. CMTG is written in Fortran IV and was developed on a DEC System-10.

Availability. Copies of the source program, a more elaborate description of it, and copies of sample output are available without charge from the authors at the Department of Psychology, Syracuse University, Syracuse, New York 13210 or from Frank A. Morisano, Board of Cooperative Educational Services, Box 233, Yorkville, New York 13495.

\section{REFERENCE NOTES}

1. JOYNER, R. C. COMTARG: Computer simulation of the common target game. Toronto: FAS, York University, 1969.

2. Morisano, F. A. Conditioning of individual behavior in the common target game. A dissertation proposal, Syracuse University, 1974.

\section{REFERENCES}

JOYNER, R. C. Computer simulation of individual concept learning in the three-person common target game. Journal of Mathematical Psychology, 1970, 7, 478-514.

JoYner, R. C., \& GREen, C. J. Demonstration of computeraugmented group problem solving. Behavioral Science, $1970,15,452-462$.

LEAVITT, H. J. Task ordering and organizational development in the common target game. Behavioral Science, 1960, 5, 233-239. 